\title{
A QM/MM Study on the Initiation Reaction of Firefly Bioluminescence-Enzymatic Oxidation of Luciferin
}

\author{
Mohan Yu ${ }^{1,2}$ and Yajun Liu ${ }^{1,3, *}$ \\ 1 Center for Advanced Materials Research, Advanced Institute of Natural Sciences, Beijing Normal University \\ at Zhuhai, Zhuhai 519087, China; tmsdtkl@foxmail.com \\ 2 School of Chemistry and Chemical Engineering, Liaoning Normal University, Dalian 116029, China \\ 3 Key Laboratory of Theoretical and Computational Photochemistry, Ministry of Education, \\ College of Chemistry, Beijing Normal University, Beijing 100875, China \\ * Correspondence: yajun.liu@bnu.edu.cn; Tel.: +86-10-58801160
}

Citation: Yu, M.; Liu, Y. A QM/MM Study on the Initiation Reaction of Firefly Bioluminescence-Enzymatic Oxidation of Luciferin. Molecules 2021, 26, 4222. https://doi.org/ $10.3390 /$ molecules 26144222

Academic Editor: Liudmil Antonov

Received: 23 June 2021

Accepted: 10 July 2021

Published: 12 July 2021

Publisher's Note: MDPI stays neutral with regard to jurisdictional claims in published maps and institutional affiliations.

Copyright: (c) 2021 by the authors. Licensee MDPI, Basel, Switzerland. This article is an open access article distributed under the terms and conditions of the Creative Commons Attribution (CC BY) license (https:// creativecommons.org/licenses/by/ $4.0 /)$.

\begin{abstract}
Among all bioluminescent organisms, the firefly is the most famous, with a high luminescent efficiency of $41 \%$, which is widely used in the fields of biotechnology, biomedicine and so on. The entire bioluminescence (BL) process involves a series of complicated in-vivo chemical reactions. The BL is initiated by the enzymatic oxidation of luciferin $\left(\mathrm{LH}_{2}\right)$. However, the mechanism of the efficient spin-forbidden oxygenation is far from being totally understood. Via MD simulation and $\mathrm{QM} / \mathrm{MM}$ calculations, this article describes the complete process of oxygenation in real protein. The oxygenation of luciferin is initiated by a single electron transfer from the trivalent anionic $\mathrm{LH}_{2}\left(\mathbf{L}^{3-}\right)$ to $\mathrm{O}_{2}$ to form ${ }^{1}\left[\mathrm{~L}^{\bullet 2-} \ldots \mathrm{O}_{2}{ }^{\bullet-}\right]$; the entire reaction is carried out along the ground-state potential energy surface to produce the dioxetanone $\left(\mathrm{FDO}^{-}\right)$via three transition states and two intermediates. The low energy barriers of the oxygenation reaction and biradical annihilation involved in the reaction explain this spin-forbidden reaction with high efficiency. This study is helpful for understanding the BL initiation of fireflies and the other oxygen-dependent bioluminescent organisms.
\end{abstract}

Keywords: firefly bioluminescence; luciferin oxidation; mechanism; single electron transfer; QM/MM

\section{Introduction}

The firefly is the most efficient bioluminescent system for converting chemical energy into light with the extremely high luminescence efficiency of $41 \%$ [1]. Its bioluminescence (BL) has been applied widely in biotechnology and biomedical fields [2,3]. The entire firefly BL process can be roughly divided into four stages (Figure 1) [4-7]: oxidation of luciferin $\left(\mathrm{LH}_{2}\right)$ to a dioxetanone (FDO), decomposition of the dioxetanone to produce excited-state oxyluciferin (bioluminophore), fluorescence emission [8-10] and $\mathrm{LH}_{2}$ regeneration. The mechanism of the last three stages has been explained theoretically in detail [11-16], but there is no comprehensive and reliable theoretical study on the mechanism of the first stage (blue dotted box in Figure 1). Oxygenation is the initial reaction for not only firefly BL but also all oxygen-dependent BL systems. A thorough and reliable investigation of this process is of great significance for understanding the mechanism of all oxygen-dependent BL [17-20].

In 2015, Branchini et al. detected the presence of superoxide anion $\left(\mathrm{O}_{2}{ }^{\bullet-}\right)$ in the chemical model reaction of firefly BL and suggested that firefly BL is induced by single electron transfer (SET) from $\mathrm{LH}^{-}$to oxygen [21]. There are some corresponding theoretical studies on the oxygenation of luciferin. In 2018, an umbrella sampling molecular dynamics simulation and QM/MM study pointed out the approach of the oxygen moving inside the protein and defined the formation of $\mathrm{FDO}^{-}$, but did not provide details along the reaction path [22]. Our group has investigated the oxygenation process in DMSO, and described a complete process with potential energy curves (PECs) of both ground state $\left(\mathrm{S}_{0}\right)$ and triplet state $\left(\mathrm{T}_{1}\right)$ to confirm the SET mechanism [23]. However, this calculation 
was not performed in the real protein, and the conclusion could not reflect the essence of the enzymatic reaction. Although there is experimental evidence and corresponding theoretical calculations, the below questions have not yet been thoroughly answered. What is the entire reaction process from $\mathrm{L}^{2-}-\mathrm{AMP}+\mathrm{O}_{2}{ }^{--}$to $\mathrm{FDO}^{-}$in protein? What is the difference between the oxygenation pathway in a solvent and in protein? How does the spin-forbidden reaction of firefly BL occur so efficiently? To answer these three questions is the purpose of this article.

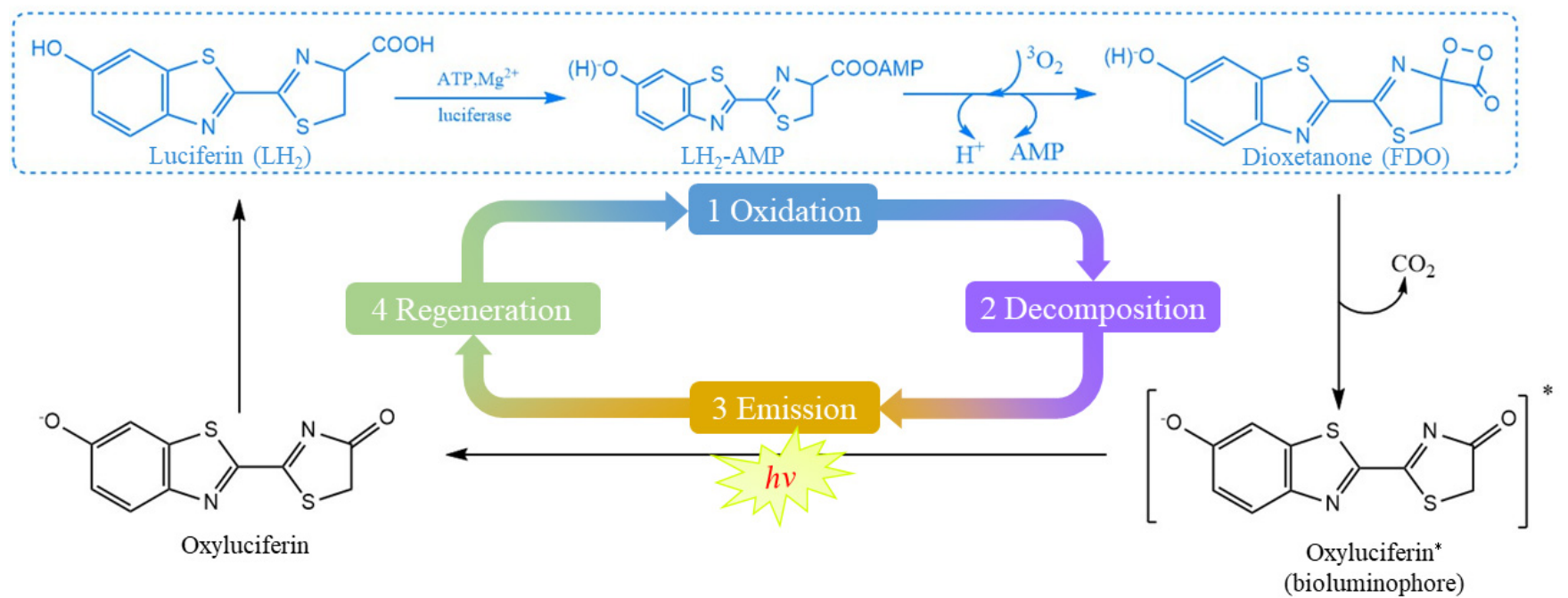

Figure 1. The four stages of a cycle of firefly bioluminescence. ${ }^{*}$ indicates the excited state.

\section{Computational Details}

For the $\mathrm{LH}_{2}$, the $\mathrm{H}$ atom on the hydroxyl in benzothiazole moiety of luciferin is easy to lose in the luciferase environment (Scheme 1). Besides, it has been proven that the dioxetanone decomposition is caused by $\mathrm{FDO}$ in its anionic form $\left(\mathrm{FDO}^{-}\right)$. In addition, the $\mathrm{H}$ atom on $\mathrm{C}_{4}$ site of LH-AMP is removed by the adjacent residue in luciferase; this process has already been verified by theoretical calculation [22]. Therefore, the complex $\mathrm{L}^{2-}$-AMP (for convenience, this trivalent complex is named $\mathbf{L}^{3-}$ ) is the actual reactant in this study. $\mathrm{L}^{2-}$ and $\mathrm{O}_{2}{ }^{-}-$are produced from SET by $\mathrm{L}^{3-}$ to $\mathrm{O}_{2}$, which induces the subsequent superoxide anion addition reaction. The North American firefly Photinus pyralis luciferase (PDB ID 4G37) [24] was chosen for its structure, which is suitable for providing a starting point for simulating the oxygenation reactions. The $2.5 \mathrm{~ns}$ molecular dynamic (MD) simulation was performed to consider protein fluctuation. The initial structures for the QM/MM calculations were started at the snapshot of 1800 ps from the MD trajectory (Figure S1). The chosen QM region contains $\mathrm{L}^{3-}$ and $\mathrm{O}_{2}$ with a total of 59 atoms, as shown in Figure 2. All QM/MM calculations were performed by a two-layered ONIOM method encoded in the Gaussian16 program [25]. The UM06-2X [26]/6-311G (d, p) [27,28] method with broken-symmetry technology was adopted for the QM region, and the remainder of the system (MM region) used the Amber force field (parm96). The QM/MM calculations and the MD simulation were based on the Gaussian 16 package [25] and AMBER 16 [29], respectively. Computational details are given in the Supporting Information. 
Adenylation

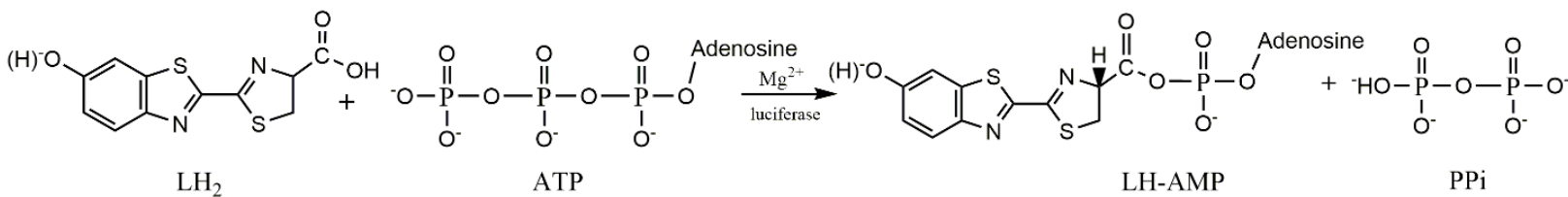

Oxygenation

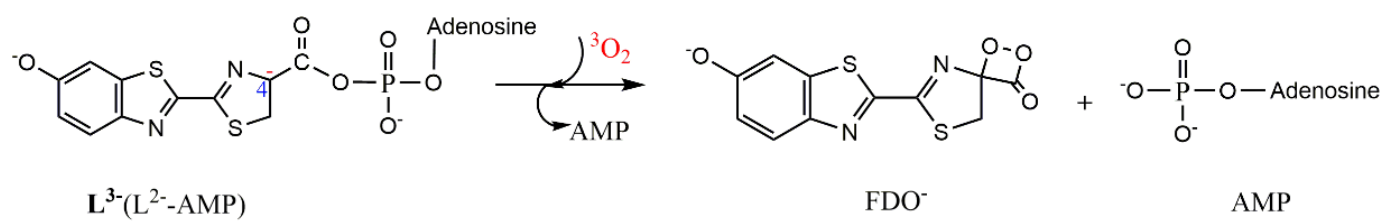

Scheme 1. Two half reactions (adenylation and oxygenation) in the initiation of firefly bioluminescence.
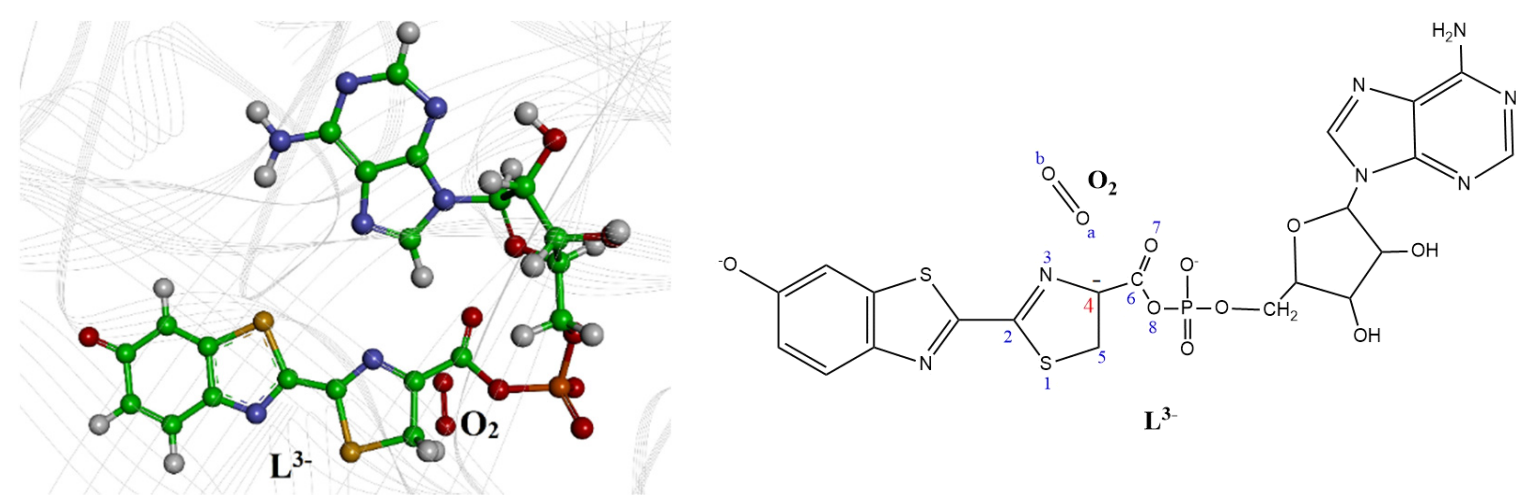

$\mathbf{L}^{3}$

Figure 2. QM/MM computational model. The gray ribbon in the background represents the protein environment (left). The atomic labels for key atoms (right). For details see Figure S2.

\section{Results and Discussion}

The firefly oxygen addition of $\mathrm{L}^{3-}$ is initiated by a SET process from $\mathrm{L}^{3-}$ to ${ }^{3} \mathrm{O}_{2}$ to produce two free doublet radicals, $\mathrm{L}^{\bullet-2-}$ and $\mathrm{O}_{2}{ }^{\bullet-}$; this reactant complex (RC) has been experimentally [21] confirmed. Since the RC is a biradical ionic pair formed by $\mathbf{L}^{\bullet 2-}$ and $\mathrm{O}_{2}{ }^{\bullet-}$ radicals, ${ }^{3}\left[\mathbf{L}^{\bullet-} \ldots \mathrm{O}_{2}{ }^{\bullet-}\right]$ and ${ }^{1}\left[\mathbf{L}^{\bullet-}{ }^{2-} \mathrm{O}_{2}{ }^{\bullet-}\right]$ are both possible initial states. For the spin density on the atom for ${ }^{3}\left[\mathbf{L}^{\bullet-} \ldots \mathrm{O}_{2}{ }^{\bullet-}\right]$ and ${ }^{1}\left[\mathbf{L}^{\bullet 2-} \ldots \mathrm{O}_{2}{ }^{\bullet-}\right]$, see Table S2. Regarding ${ }^{1}\left[\mathrm{~L}^{\bullet-} \ldots \mathrm{O}_{2}{ }^{\bullet-}\right]$ as the initial state, from $\mathrm{RC}$ to the final product $\mathrm{FDO}^{-}$and AMP (for convenience, we defined $\mathrm{FDO}^{-}+\mathrm{AMP}$ as $\mathrm{P}$ ), three transitions states (TSs) and two intermediates (Ints) were located. The relative energy profiles of SET oxygenation on $\mathbf{L}^{3-}$ are shown in Figure 3. The key geometric parameters and Mulliken charges population for all stationary points on $\mathbf{L}^{\bullet-}$ and $\mathrm{O}_{2}{ }^{\bullet-}$ moieties are summarized in Table 1 . As shown in Figure 3, the $\mathrm{RC}^{1}\left[\mathbf{L}^{\bullet-} \ldots \mathrm{O}_{2}{ }^{\bullet-}\right]\left({ }^{1} \mathrm{RC}\right)$ is formed by electrostatic force and van der Waals interaction. The $\mathrm{O}_{a}-\mathrm{O}_{\mathrm{b}}$ bond distance is $1.311 \AA$ in ${ }^{1} \mathrm{RC}$, which is longer than it is in ${ }^{3} \mathrm{O}_{2}(1.205 \AA)$. This implies that $\mathrm{O}_{2}{ }^{\bullet-}$, rather than ${ }^{3} \mathrm{O}_{2}$, attacks the $\mathrm{L}^{\bullet 2-}$. The charge distribution of $\mathrm{O}_{2}{ }^{\bullet-}$ is $-1.00 \mathrm{l}$ e I when it is just generated via the SET process. However, partial negative charge transferred from $\mathrm{O}_{2}{ }^{\bullet-}$ to $\mathrm{L}^{\bullet 2-}$ in the formation of ${ }^{1} \mathrm{RC}$, and the Mulliken charge on $\mathrm{O}_{2}{ }^{\bullet-}$ is $-0.88 \mathrm{I} \mathrm{e}$ and $-2.12 \mathrm{le}$ l on $\mathrm{L}^{\cdot 2-}$. The expectation value of the $S^{2}$ operator $\left.\left(<S^{2}\right\rangle\right)$ is 1.00 , which indicates that the ${ }^{1} R C$ has obvious biradical characteristics. With the process of nucleophilic addition, the $\mathrm{C}_{4}-\mathrm{O}_{a}$ bond becomes shorter and the $\mathrm{C}_{6}-\mathrm{C}_{4}$ $\mathrm{O}_{\mathrm{a}}-\mathrm{O}_{\mathrm{b}}$ dihedral angle gradually twists to the closure of four-membered cyclic peroxide. ${ }^{1} \mathrm{RC}$ forms Int1 through TS1 via a biradical annihilation. This process is accompanied by a small amount of back negative charge transfer (CT) from $\mathrm{L}^{\bullet-}$ to $\mathrm{O}_{2}{ }^{\bullet-}$ (see Table 1). The 
bond length of $\mathrm{C}_{4}-\mathrm{O}_{a}$ is $1.401 \AA$ in Int1, which does not change much until TS2. Int1 forms Int2 with a four-membered cyclic structure through TS2.

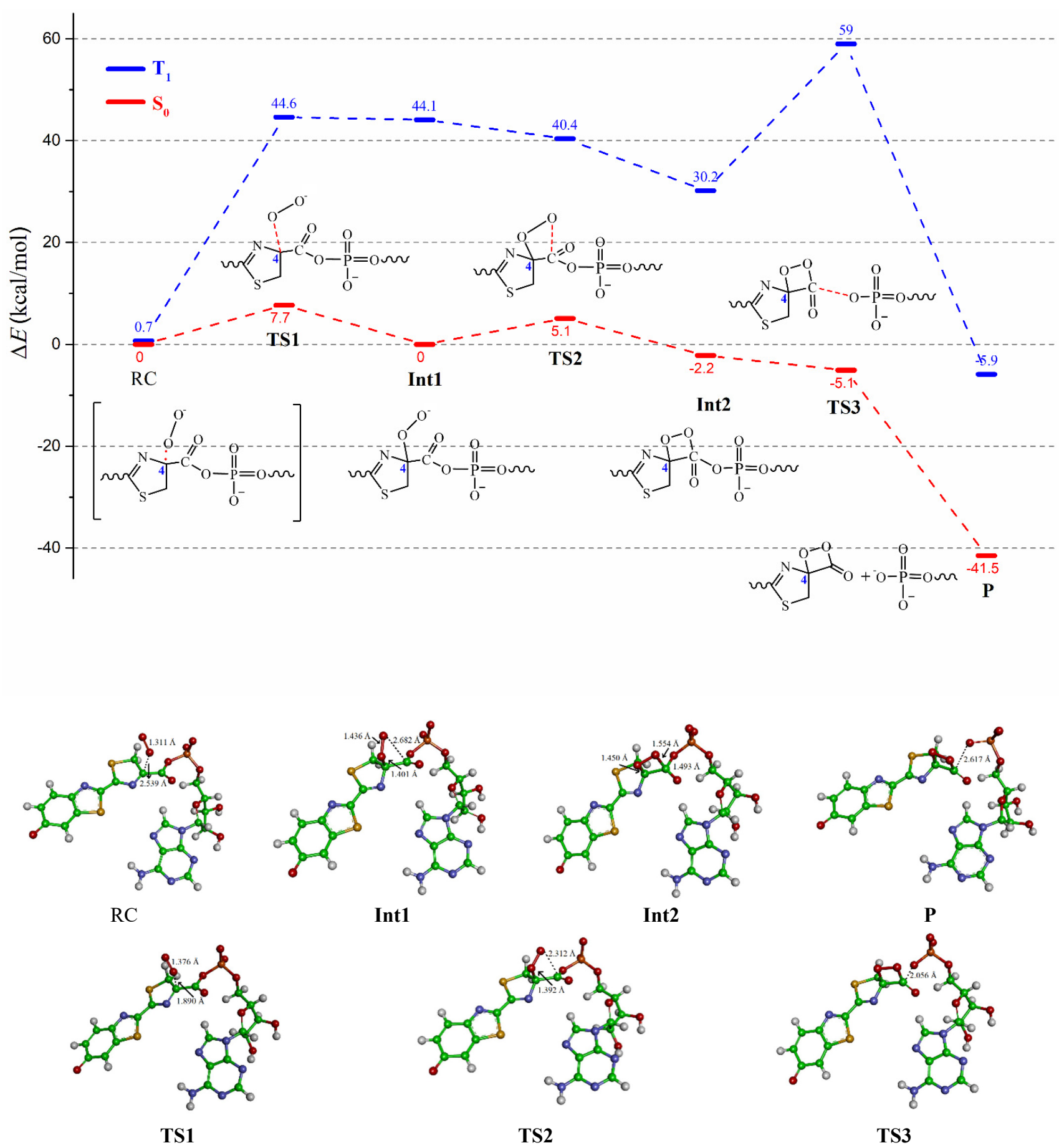

Figure 3. The $\mathrm{S}_{0}$ and $\mathrm{T}_{1}$ relative energy profile of the stationary points for oxygenation of $\mathbf{L}^{3-}$ in protein by ONIOM (UM06-2X/MM) method. (The unit of energies is $\mathrm{kcal} \mathrm{mol}^{-1}$ ) Here and in later figures, carbon atoms are shown in green, oxygen in red, nitrogen in blue, phosphorus in orange and hydrogen in white. 
Table 1. The key geometric parameters (in $\AA$ and degrees) and the Mulliken charges population on $\mathrm{L}^{\bullet 2-}$ and $\mathrm{O}_{2} \bullet-$ of the stationary points of $\mathbf{L}^{3-}$ oxygenation by ONIOM method (UM06-2X/MM). (See atomic labels in Figure 2).

\begin{tabular}{|c|c|c|c|c|c|c|c|c|c|}
\hline & $\mathrm{O}_{\mathrm{a}}-\mathrm{O}_{\mathrm{b}}$ & $\mathrm{C}_{4}-\mathrm{C}_{6}$ & $\mathrm{C}_{6}-\mathrm{O}_{7}$ & $\mathrm{C}_{6}-\mathrm{O}_{8}$ & $\mathrm{C}_{4}-\mathrm{O}_{\mathrm{a}}$ & $\mathrm{C}_{6}-\mathrm{O}_{\mathrm{b}}$ & $\mathrm{C}_{6}-\mathrm{C}_{4}-\mathrm{O}_{\mathrm{a}}-\mathrm{O}_{\mathrm{b}}$ & $\rho\left(\mathrm{O}^{2 \bullet-}\right)$ & $\rho\left(\mathrm{L}^{\bullet 2-}\right)$ \\
\hline${ }^{1} \mathrm{RC}$ & 1.311 & 1.462 & 1.206 & 1.412 & 2.539 & 3.358 & 119.8 & -0.88 & -2.12 \\
\hline TS1 & 1.376 & 1.493 & 1.201 & 1.390 & 1.890 & 3.139 & 118.2 & -0.98 & -2.02 \\
\hline Int1 & 1.436 & 1.568 & 1.200 & 1.370 & 1.401 & 2.682 & 63.0 & -1.01 & -1.99 \\
\hline TS2 & 1.440 & 1.576 & 1.198 & 1.386 & 1.392 & 2.321 & 49.8 & -0.92 & -2.07 \\
\hline Int2 & 1.446 & 1.598 & 1.232 & 1.493 & 1.450 & 1.554 & 17.9 & -0.69 & -2.31 \\
\hline TS3 & 1.447 & 1.552 & 1.185 & 2.056 & 1.476 & 1.416 & 1.3 & -0.56 & -2.44 \\
\hline $\mathbf{P}$ & 1.445 & 1.530 & 1.178 & 2.617 & 1.494 & 1.375 & -5.1 & -0.52 & -2.48 \\
\hline
\end{tabular}

The main structural changes from Int1 to Int2 are the shortening of the $\mathrm{C}_{6}-\mathrm{O}_{\mathrm{b}}$ bond and the torsion of the $\mathrm{C}_{6}-\mathrm{C}_{4}-\mathrm{O}_{\mathrm{a}}-\mathrm{O}_{\mathrm{b}}$ dihedral angle, which are accompanied by an obvious negative $\mathrm{CT}$ from $\mathrm{O}_{2}{ }^{\bullet-}$ to $\mathrm{L}^{\bullet-}$ (see Table 1 ). The bond length of $\mathrm{C}_{6}-\mathrm{O}_{8}$ does not change much until Int2. After Int2, the $\mathrm{C}_{6}-\mathrm{O}_{8}$ bond began to break and leads to $\mathbf{P}$ with the departure of the AMP group. This process is accompanied by $-0.17 \mathrm{CT}$ from $\mathrm{O}_{2}{ }^{\bullet-}$ to $\mathrm{L}^{\bullet 2-}$ and adjustment of the $\mathrm{C}_{6}-\mathrm{C}_{4}-\mathrm{O}_{\mathrm{a}}-\mathrm{O}_{\mathrm{b}}$ dihedral angle. (See Table 1).

For the case of ${ }^{3}\left[\mathrm{~L}^{\bullet 2-} \ldots \mathrm{O}_{2}{ }^{\bullet-}\right]$ as the initial state, the energies of all stationary points at the $T_{1}$ state were evaluated at the corresponding $S_{0}$ geometries, except ${ }^{3} \mathrm{RC}$ was optimized (Figure S3). The optimized ${ }^{3}\left[\mathrm{~L}^{\bullet 2-} \ldots \mathrm{O}_{2}{ }^{\bullet-}\right]$ is $0.7 \mathrm{kcal} \mathrm{mol}^{-1}$ higher than ${ }^{1}\left[\mathrm{~L}^{\bullet-} \ldots \mathrm{O}_{2}{ }^{\bullet-}\right]$. The ${ }^{3}\left[\mathrm{~L}^{\bullet-} \ldots \mathrm{O}_{2}{ }^{\bullet-}\right]$ at the ${ }^{1}\left[\mathrm{~L}^{\bullet-} \ldots \mathrm{O}_{2}{ }^{\bullet-}\right]$ geometry is $1.6 \mathrm{kcal} \mathrm{mol}^{-1}$ higher than ${ }^{1}\left[\mathrm{~L}^{\bullet-} \ldots \mathrm{O}_{2}{ }^{\bullet-}\right]$. Except for ${ }^{3}\left[\mathrm{~L}^{\bullet 2-} \ldots \mathrm{O}_{2}{ }^{\bullet-}\right]$, the energy of each stationary point on the $\mathrm{T}_{1} \mathrm{PEC}$ is much higher than the corresponding one on the $\mathrm{S}_{0}$ PEC. Obviously, the $\mathrm{LH}_{2}$ oxygenation reaction occurs on the $\mathrm{S}_{0}$ potential energy surface (PES). It is worth mentioning that this is quite different from our previous calculation in DMSO [23]. In a solvent, the reaction first occurs along the $\mathrm{T}_{1}$ PES; after an intersystem crossing (ISC), the reaction takes place on the $S_{0}$ PES. Meanwhile, the biradical annihilation occurs along with the ISC process and finally a four-membered cyclic structure is formed (Figure S4). However, in luciferase, the reaction always occurs on the $S_{0}$ PES and does not need to pass an ISC, which definitely increases the reaction efficiency. Along the reaction process, the highest energy barrier is $7.7 \mathrm{kcal} \mathrm{mol}^{-1}$, which is lower than the highest energy barrier of $11.9 \mathrm{kcal} \mathrm{mol}^{-1}$ in a solvent (Figure S4).

To further probe the effect of enzymatic catalysis in the process of $\mathrm{LH}_{2}$ oxidation, we carefully investigated the important interactions between the QM region and the residues in active-site residues (see Figure 4). According to the above computational results in the protein, the rate-determined step in the complete process of the $\mathrm{LH}_{2}$ oxygenation is from ${ }^{1} \mathrm{RC}$ to Int1. Therefore, our analysis focuses on the structures of ${ }^{1} \mathrm{RC}$, TS1 and Int1. F-shaped $\pi-\pi$ stacking forming between Phe-247 and $\mathbf{L}^{\bullet 2-}$ is important for stabilizing the aromatic part of the benzothiazole moiety of $\mathbf{L}^{\bullet 2-}$; this interaction exists all throughout the oxygenation. Besides, His-245 and Lys- 433 had a strong H-bond interaction with the $\mathrm{O}$ atom on the AMP moiety of $\mathbf{L}^{3-}$. Lys- 433 and $\mathrm{O}_{7}$ of $\mathbf{L}^{3-}$ also formed an $\mathrm{H}$-bond. These $\mathrm{H}$-bond interactions between positively charged residues and substrates lead to the negative charge of $\mathrm{O}_{2}{ }^{\bullet-}$ and $\mathbf{L}^{\bullet-}$ moiety decrease. The $\mathrm{H}$-bond interaction with $2.453 \AA$ between Gly-246 and $\mathrm{O}_{2}{ }^{\bullet-}$ affects the relative position of $\mathrm{O}_{2}{ }^{--}$and $\mathbf{L}^{\bullet-}$. With the $\mathrm{C}_{6}-\mathrm{C}_{4-}$ $\mathrm{O}_{\mathrm{a}}-\mathrm{O}_{\mathrm{b}}$ dihedral angle gradual torsion, the $\mathrm{H}$-bond between Gly-246 and $\mathrm{O}_{2}{ }^{\bullet-}$ becomes slightly strong, and then changes to $2.647 \AA$ as Int1 is formed. Meanwhile, His-245 with $\mathrm{O}_{\mathrm{b}}$ forms a weak $\mathrm{H}$-bond. In short, these results demonstrated that the hydrogen-bond interactions between Gly-246 and $\mathrm{O}_{2}{ }^{\bullet-}$ are essential for the process of oxygen addition. The hydrogen-bonding interactions between Lys-433 and His-245 with AMP moiety of $\mathbf{L}^{3-}$ majorly stabilize the substrate and the negative charge on the $\mathrm{O}$ atom of AMP. 


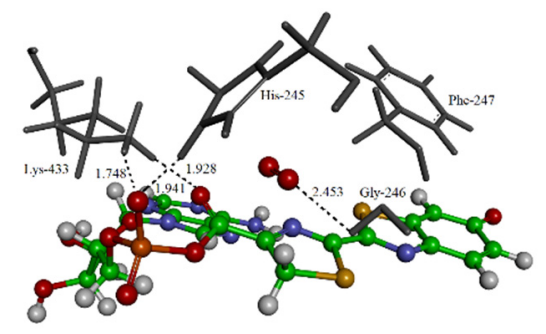

$\mathrm{RC}$

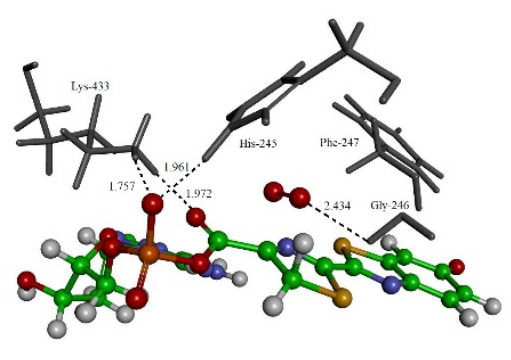

TS1

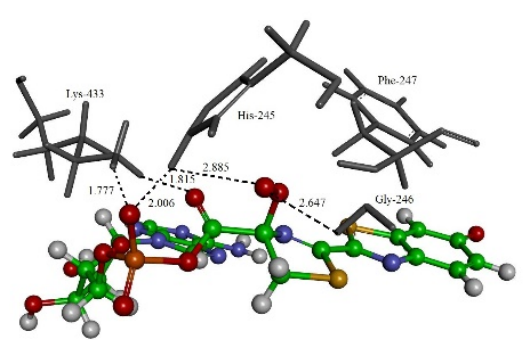

Int1

Figure 4. The interactions between RC, TS1, Int1 and residues in an active site by ONIOM method (UM06-2X/MM). (The protein environment is not shown).

\section{Conclusions}

Firefly BL is initiated by the reaction of $\mathrm{LH}_{2}+{ }^{3} \mathrm{O}_{2}$. This is a spin-forbidden reaction with usually a low efficiency, which contradicts the fact that the firefly is the most efficient bioluminescent system for converting chemical energy into light. In this letter, we addressed this issue via MD and QM/MM studies. In luciferase, the entire reaction starts with a SET process and occurs all along the $S_{0} P E S$. This is quite different for the reaction in a solvent, where the reaction first occurs along the $T_{1} P E S$ and then along the $S_{0} P E S$ after an intersystem crossing (ISC). Moreover, the rate-determined step obviously has a lower barrier in luciferase than in a solvent. The effect of enzymatic catalysis was analyzed. The present theoretical study provides strong theoretical evidence for the SET mechanism of $\mathrm{LH}_{2}$ oxygenation of firefly BL, and is helpful for understanding the BL initiation of the other oxygen-dependent bioluminescent organisms.

Supplementary Materials: The following are available online. Computational details; the protonation states of Histidine; figure of molecular dynamics simulation; figure of QM/MM computational model; figure of optimized structure of RC; figures of computational model in DMSO; figure of $\mathrm{S}_{0}$ and $\mathrm{T}_{1}$ PECs of oxygenation in DMSO; Cartesian coordinates. Table S1: The protonation states of Histidine residue are computed by $\mathrm{H}++$ program at $\mathrm{pH}=7.8$. Figure $\mathrm{S} 1$ : $\mathrm{RMS}$ deviation of firefly luciferase backbone during 2.5 ns molecular dynamics simulation, Figure S2: QM/MM computational model, Figure S3: The optimized structure of RC, Figure S4: (a) Computational model in DMSO and labels of key atoms. (b) S0 and T1 PECs of oxygenation of A3- in DMSO at UM06-2X/6-31G (d, p) level, Table S2: The spin densities of RC.

Author Contributions: Manuscript conception, Y.L.; writing-original draft preparation, M.Y.; writing-review and editing, Y.L.; calculation, M.Y.; methodology, Y.L. All authors have read and agreed to the published version of the manuscript.

Funding: This research was funded by the National Natural Science Foundation of China (Grant Nos. 21973005).

Institutional Review Board Statement: Not applicable.

Informed Consent Statement: Not applicable.

Data Availability Statement: Data are available from the authors.

Conflicts of Interest: The authors declare no conflict of interest.

Sample Availability: Samples of the compounds are available from the authors.

\section{References}

1. Ando, Y.; Niwa, K.; Yamada, N.; Enomot, T.; Irie, T.; Kubota, H.; Ohmiya, Y.; Akiyama, H. Firefly bioluminescence quantum yield and colour change by $\mathrm{pH}$-sensitive green emission. Nat. Photonics. 2008, 2, 44-47. [CrossRef]

2. Kuchimaru, T.; Iwano, S.; Kiyama, M.; Mitsumata, S.; Kadonosono, T.; Niwa, H.; Maki, S.; Kizaka-Kondoh, S. A luciferin analogue generating near-infrared bioluminescence achieves highly sensitive deep-tissue imaging. Nat. Commun. 2016, 7, 11856. [CrossRef] [PubMed] 
3. Negrin, R.S.; Contag, C.H. Innovation-In vivo imaging using bioluminescence: A tool for probing graft-versus-host disease. Nat. Rev. Immunol. 2006, 6, 484-490. [CrossRef] [PubMed]

4. Vacher, M.; Galvan, I.F.; Ding, B.-W.; Schramm, S.; Berraud-Pache, R.; Naumov, P.; Ferre, N.; Liu, Y.-J.; Navizet, I.; Roca-Sanjuan, D.; et al. Chemi- and Bioluminescence of Cyclic Peroxides. Chem. Rev. 2018, 118, 6927-6974. [CrossRef] [PubMed]

5. Wood, K.V. The chemical mechanism and evolutionary development of beetle bioluminescence. Photochem. Photobiol. 1995, 62, 662-673. [CrossRef]

6. Schmidt, S.P.; Schuster, G.B. Dioxethanone Chemiluminescence by Chemically-Initiated Electron Exchange Pathway-Efficient Generation of Excited Singlet-States. J. Am. Chem. Soc. 1978, 100, 1966-1968. [CrossRef]

7. Navizet, I.; Liu, Y.-J.; Ferre, N.; Roca-Sanjuan, D.; Lindh, R. The Chemistry of Bioluminescence: An Analysis of Chemical Functionalities. Chemphyschem 2011, 12, 3064-3076. [CrossRef]

8. Navizet, I.; Liu, Y.-J.; Ferre, N.; Xiao, H.-Y.; Fang, W.-H.; Lindh, R. Color-Tuning Mechanism of Firefly Investigated by MultiConfigurational Perturbation Method. J. Am. Chem. Soc. 2010, 132, 706-712. [CrossRef]

9. Chen, S.-F.; Liu, Y.-J.; Navizet, I.; Ferre, N.; Fang, W.-H.; Lindh, R. Systematic Theoretical Investigation on the Light Emitter of Firefly. J. Chem. Theory. Comput. 2011, 7, 798-803. [CrossRef]

10. Da Silva, L.P.; Esteves da Silva, J.C.G. Quantum/molecular mechanics study of firefly bioluminescence on luciferase oxidative conformation. Chem. Phys. Lett. 2014, 608, 45-49. [CrossRef]

11. Orlova, G.; Goddard, J.D.; Brovko, L.Y. Theoretical study of the amazing firefly bioluminescence: The formation and structures of the light emitters. J. Am. Chem. Soc. 2003, 125, 6962-6971. [CrossRef]

12. Yue, L.; Liu, Y.-J.; Fang, W.-H. Mechanistic Insight into the Chemiluminescent Decomposition of Firefly Dioxetanone. J. Am. Chem. Soc. 2012, 134, 11632-11639. [CrossRef]

13. Yue, L.; Lan, Z.; Liu, Y.-J. The Theoretical Estimation of the Bioluminescent Efficiency of the Firefly via a Nonadiabatic Molecular Dynamics Simulation. J. Phys. Chem. Lett. 2015, 6, 540-548. [CrossRef] [PubMed]

14. Cheng, Y.-Y.; Liu, Y.-J. Luciferin Regeneration in Firefly Bioluminescence via Proton-Transfer-Facilitated Hydrolysis, Condensation and Chiral Inversion. Chem. Phys. Chem. 2019, 20, 1719-1727. [CrossRef]

15. Da Silva, L.P.; Esteves da Silva, J.C.G. Firefly Chemiluminescence and Bioluminescence: Efficient Generation of Excited States. Chem. Phys. Chem. 2012, 13, 2257-2262. [CrossRef] [PubMed]

16. Da Silva, L.P.; Esteves da Silva, J.C.G. Study on the Effects of Intermolecular Interactions on Firefly Multicolor Bioluminescence. Chem. Phys. Chem. 2011, 12, 3002-3008. [CrossRef] [PubMed]

17. Dubinnyi, M.A.; Tsarkova, A.S.; Petushkov, V.N.; Kaskova, Z.M.; Rodionova, N.S.; Kovalchuk, S.I.; Ziganshin, R.H.; Baranov, M.S.; Mineev, K.S.; Yampolsky, I.V. Novel Peptide Chemistry in Terrestrial Animals: Natural Luciferin Analogues from the Bioluminescent Earthworm Fridericia heliota. Chem. Eur. J. 2015, 21, 3942-3947. [CrossRef]

18. Winkler, U.K.; Sicher, J. Bioluminescence of animals, plants and bacteria. Naturwissenschaften 1996, 83, 312-320. [CrossRef]

19. Shimomura, O.; Johnson, F.H. Structure of Latia luciferin. Biochemistry 1968, 7, 1734. [CrossRef]

20. Ding, B.-W.; Naumov, P.; Liu, Y.-J. Mechanistic Insight into Marine Bioluminescence: Photochemistry of the Chemiexcited Cypridina (Sea Firefly) Lumophore. J. Chem. Theory. Comput. 2015, 11, 591-599. [CrossRef] [PubMed]

21. Branchini, B.R.; Behney, C.E.; Southworth, T.L.; Fontaine, D.M.; Gulick, A.M.; Vinyard, D.J.; Brudvig, G.W. Experimental Support for a Single Electron-Transfer Oxidation Mechanism in Firefly Bioluminescence. J. Am. Chem. Soc. 2015, 137, 7592-7595. [CrossRef] [PubMed]

22. Berraud-Pache, R.; Lindh, R.; Navizet, I. QM/MM Study of the Formation of the Dioxetanone Ring in Fireflies Through a Superoxide Ion. J. Phys. Chem. B 2018, 122, 5173-5182. [CrossRef] [PubMed]

23. Yu, M.; Cheng, Y.; Liu, Y. Mechanistic Study of Oxygenation Reaction in Firefly Bioluminescence. Acta Chim. Sin. 2020, 78, 989-993. [CrossRef]

24. Sundlov, J.A.; Fontaine, D.M.; Southworth, T.L.; Branchini, B.R.; Gulick, A.M. Crystal Structure of Firefly Luciferase in a Second Catalytic Conformation Supports a Domain Alternation Mechanism. Biochemistry 2012, 51, 6493-6495. [CrossRef]

25. Frisch, M.J.; Trucks, G.W.; Schlegel, H.B.; Scuseria, G.E.; Robb, M.A.; Cheeseman, J.R.; Scalmani, G.; Barone, V.; Petersson, G.A.; Nakatsuji, H.; et al. Gaussian 16 Revision B.01; Gaussian, Inc.: Wallingford, UK, 2016.

26. Zhao, Y.; Truhlar, D.G. The M06 suite of density functionals for main group thermochemistry, thermochemical kinetics, noncovalent interactions, excited states, and transition elements: Two new functionals and systematic testing of four M06-class functionals and 12 other functionals. Theor. Chem. Acc. 2007, 120, 215-241.

27. McLean, A.D.; Chandler, G.S. Contracted Gaussian-Basis Sets For Molecular Calculations 1. 2ND Row Atoms, Z=11-18. J. Chem. Phys. 1980, 72, 5639-5648. [CrossRef]

28. Krishnan, R.; Binkley, J.S.; Seeger, R.; Pople, J.A. Self-Consistent Molecular-Orbital Methods 20. Basis Set for Correlated Wave-Functions. J. Chem. Phys. 1980, 72, 650-654. [CrossRef]

29. Case, D.A.; Betz, R.M.; Cerutti, D.S.; Cheatham, T.E., III; Darden, T.A.; Duke, R.E.; Giese, T.J.; Gohlke, H.; Goetz, A.W.; Homeyer, N.; et al. AMBER 2016; University of California: San Francisco, CA, USA, 2016. 